Respiration 2016;92:61-62

DOI: $10.1159 / 000447642$

\section{Validity and Reliability Concerns Associated with Cardiopulmonary Exercise Testing Young People with Cystic Fibrosis}

\author{
Zoe L. Saynor $^{\text {a }}$ Alan R. Barker ${ }^{\text {b Patrick J. Oades }}{ }^{c}$ \\ Owen W. Tomlinson ${ }^{b}$ Craig A. Williams ${ }^{b}$ \\ ${ }^{a}$ Department of Sport and Exercise Science, University of \\ Portsmouth, Portsmouth, ${ }^{\mathrm{b}}$ Children's Health and Exercise \\ Research Centre, Sport and Health Sciences, University of \\ Exeter, and 'Paediatric Unit, Royal Devon and Exeter NHS \\ Foundation Trust, Exeter, UK
}

The recent statement by Hebestreit and colleagues [1] on behalf of the European Cystic Fibrosis Society (ECFS) Exercise Working Group and endorsed by the European Respiratory Society should be commended for their efforts to establish consensus regarding exercise testing for young people with cystic fibrosis (CF). Exercise testing is a valuable investigative tool for the clinical management and scientific investigation of children and adolescents with CF and this document provides an international standpoint regarding the importance of cardiopulmonary exercise testing (CPET) within the management of this patient group. However, it is our view that the authors have missed an opportunity to provide a contemporary and comprehensive overview of the CPET 'toolkit' currently available.

The authors state that this document will 'describe the current best practice recommendations for conducting exercise tests in patients with CF' and 'summarises the information available on specific test protocols and outcome parameters' (page 2). The authors recommend the Godfrey protocol [2] when using the cycle ergometer, with measures of arterial oxygen saturation and, when possible, pulmonary gas exchange and ventilation. Whilst this does represent progress from the routinely used shuttle and step tests, the authors failed to acknowledge several limitations inherent to the Godfrey protocol and the recommended use of criteria to verify a maximal test. This is surprising, given that the ECFS Clinical Trials Network Standardisation Committee recently called for research assessing the validity, reproducibility and feasibility of outcome measures utilised in the assessment of patients with $\mathrm{CF}$ and the most appropriate exercise test for paediatric patients [3].

The authors rightfully acknowledge that an issue with shuttle and step tests is that it can be difficult to determine whether a maximal effort was made. However, they then state that 'the Godfrey protocol provides valid information for all CF relevant indications for an exercise test'. The authors recommend that since not all individuals display the tradition verification criterion of a pla- teau in oxygen uptake $\left(\mathrm{VO}_{2}\right)$ upon exhaustion, at least one of the following should be used to confirm a maximal effort: the patient achieves a predicted $\dot{\mathrm{VO}}_{2}$ peak or peak power output $\left(\mathrm{W}_{\text {peak }}\right)$, the patient reaches maximal heart rate $\left(\mathrm{HR}_{\max }\right)$, peak ventilation approaches maximal voluntary ventilation, respiratory exchange ratio (RER) is $>1.03$, exertion is $9-10$ on the $0-10$ scale or $\geq 17$ on a 7-20 scale. However, our research group recently demonstrated that the use of secondary criteria to confirm a maximal effort (e.g. RER $>1.00$ or 1.10 , HR of 180 beats $\cdot \mathrm{min}^{-1}$ or $95 \%$ age-predicted $\mathrm{HR}_{\max }$ ), in line with those recommended by Hebestreit et al. [1], are invalid and can drastically underreport $\mathrm{VO}_{2}$ max in some young people with CF [4], a finding consistent with healthy children and adolescents [5]. Accepting submaximal or rejecting 'true' maximal values can distort the clinical application and interpretation of CPET, which is important given that $\dot{\mathrm{VO}}_{2}$ max is an indicator of prognosis [6, 7], quality of life [8] and risk of hospitalisation for exacerbations [9] in people with CF.

Given the limited use of secondary verification criteria to verify a maximal CPET effort in young people with CF, we have developed an alternative protocol to do so. A procedure termed the 'supramaximal verification phase' $\left(S_{\max }\right)$, in which an exhaustive ramp incremental test preceding an exhaustive individualised constant work rate test at an intensity above $\mathrm{W}_{\text {peak }}$ can confirm whether a 'true' measure of $\mathrm{VO}_{2 \text { max }}$ has been obtained, which is fundamental to the utility of this outcome parameter in CF. Significantly, this finding is in line with data in healthy adults [10-18], children [5] and other paediatric clinical groups [19]. Although the authors present information regarding 'was the test maximal?', they failed to reference this published evidence and presented inaccurate verification criteria as 'best' CPET practice for young people with CF, which we feel should be approached with caution. This statement also provides a summary of the reliability of exercise tests for young people with CF; however, again published evidence has been ignored. We recently reported both the short- and medium-term reproducibility of a valid CPET protocol for young people with CF [4], which was shown to reduce the error of measurement when compared with an isolated incremental CPET to derived $\mathrm{VO}_{2}$ peak [20]. To the best of our knowledge, we are not aware of any reproducibility or validity data for $\dot{\mathrm{VO}}_{2 \text { max }}$ in young people with CF derived using the Godfrey protocol.

Whilst the focus of this letter addresses validity and reproducibility issues with the Godfrey protocol, other important issues to consider are: 'step' increases in work rate derived exclusively from stature can result in insufficient test durations of $\leq 4 \mathrm{~min}$ [21]. This procedure limits our ability to characterise the progressive increase in $\mathrm{VO}_{2}$ during exercise and determine submaximal measures of aerobic fitness (e.g. the gas exchange threshold or $\mathrm{VO}_{2}$ mean response time), which, as highlighted in this consensus statement, may provide better predictors of mortality in adolescents with $\mathrm{CF}$ [22]. In accordance with others [23], we recommend a ramp incremental exercise test, which aims to reach volitional exhaustion in 8-12 $\min$ [24], followed by $S_{\max }$ verification of maximal CPET pa-

\section{KARGER}

E-Mail karger@karger.com

www.karger.com/res
2016 S. Karger AG, Basel

0025-7931/16/0921-0061\$39.50/0
Dr. Zoe L. Saynor

Department of Sport and Exercise Science

Spinnaker Building, Cambridge Road

University of Portsmouth, Portsmouth PO1 2ER (UK)

E-Mail zoe.saynor@ port.ac.uk 
rameters. Not only has this testing protocol been demonstrated as safe and feasible in young people with CF in a research setting, it is also now used as part of patients' annual clinical review with UKbased CF clinics in Exeter and Southampton, demonstrating the feasibility of its clinical implementation. The CF-specific linear regression model to predict $\mathrm{W}_{\text {peak }}$ and calculate individualised workload increments to reach volitional exhaustion in $\sim 10 \mathrm{~min}$ developed by Hulzebos and colleagues [25] should help prevent short test durations.

Whilst it is recognised that there are no large-scale studies directly comparing exercise testing protocols, we feel the authors could have provided a more contemporary overview of the evidence concerning the validity and reproducibility of CPET protocols available for use in young people with CF. If the clinical utility of CPET to provide a comprehensive evaluation of physiological (dys)function and stratify patients with CF is to be realised, these important practical considerations must be acknowledged.

\section{References}

1 Hebestreit H, Arets HGM, Aurora P, Boas S, Cerny F, Hulzebos EHJ Karila C, Lands LC, Lowman JD, Swisher A, Urquart DS; European Cystic Fibrosis Exercise Working Group: Statement on exercise testing in cystic fibrosis. Respiration 2015;90:332-351.

-2 Godfrey S, Davies CT, Wozniak E, Barnes CA: Cardio-respiratory response to exercise in normal children. Clin Sci 1971;40:419-431.

-3 Bradley JM, Madge S, Morton AM, Quittner AL, Elborn JS: Cystic fibrosis research in allied health and nursing professions. J Cyst Fibros 2012; 11:387-392.

-4 Saynor ZL, Barker AR, Oades PJ, Williams CA: A protocol to determine valid $\mathrm{O}_{2 \max }$ in young cystic fibrosis patients. J Sci Med Sport 2013;16: 539-544.

-5 Barker AR, Williams CA, Jones AM, Armstrong N: Establishing maximal oxygen uptake in young people during a ramp cycle test to exhaustion. Br J Sports Med 2011;45:498-503.

6 Nixon PA, Orenstein DM, Kelsey SF, Doershuk CF: The prognostic value of exercise testing in patients with cystic fibrosis. N Engl J Med 1992; 327:1785-1788.

7 Pianosi P, Leblanc J, Almudevar A: Peak oxygen uptake and mortality in children with cystic fibrosis. Thorax 2005;60:50-54.

$\checkmark 8$ De Jong W, Kaptein AA, van der Schans CP, Mannes GP, van Aalderen WM, Grevink RG, Koëter GH: Quality of life in patients with cystic fibrosis. Pediatr Pulmonol 1997;23:95-100.

9 Pérez M, Groeneveld IF, Santana-Sosa E, Fiuza-Luces C, Gonzalez-Saiz L, Villa-Asensi JR, López-Mojares LM, Rubio M, Lucia A: Aerobic fitness is associated with lower risk of hospitalization in children with cystic fibrosis. Pediatr Pulmonol 2014;49:641-649.
10 Day JR, Rossiter HB, Coats EM, Skasick A, Whipp BJ: The maximally attainable $\mathrm{O}_{2}$ during exercise in humans: the peak vs. maximum issue. J Appl Physiol 2003;95:1901-1907.

11 Midgley AW, McNaughton LR, Carroll S: Verification phase as a useful tool in the determination of the maximal oxygen uptake of distance runners. Appl Physiol Nutr Metab 2006;31:541-548.

12 Rossiter HB, Kowalchuk JM, Whipp BJ: A test to establish maximum $\mathrm{O}_{2}$ uptake despite no plateau in the $\mathrm{O}_{2}$ uptake response to ramp incremental exercise. J Appl Physiol 2006;100:764-770.

13 Midgley AW, McNaughton LR, Polman R, Marchant D: Criteria for determination of maximal oxygen uptake: a brief critique and recommendations for future research. Sports Med 2007;37:1019-1028.

14 Hawkins MN, Raven PB, Snell PG, Stray-Gundersen J, Levine BD: Maximal oxygen uptake as a parametric measure of cardiorespiratory capacity. Med Sci Sports Exerc 2007;39:103-107.

15 Foster C, Kuffel E, Bradley N, Battista RA, Wright G, Porcari JP, Lucia A, deKoning JJ: VO2max during successive maximal efforts. Eur J Appl Physiol 2007;102:67-72.

16 Poole DC, Wilkerson DP, Jones AM: Validity for establishing maximal $\mathrm{O}_{2}$ uptake during ramp exercise tests. Eur J Appl Physiol 2008;102:403410.

17 Midgley AW, Carrol S: Emergence of the verification phase procedure for confirming 'true' VO(2max). Scand J Med Sci Sports 2009;19:313322 .

18 Scharhag-Rosenberger F, Carlsohn A, Cassel M, Mayer F, Scharhag J: How to test maximal oxygen uptake: a study on timing and testing procedure of a supramaximal verification test. Appl Physiol Nutr Metab 2011;36:153-160.

19 de Groot JF, Takken T, de Graaf S, Gooskens RH, Helders PJ, Vanhees L: Treadmill testing of children who have spina bifida and are ambulatory: does peak oxygen uptake reflect maximum oxygen uptake? Phys Ther 2009;89:679-687.

20 Saynor ZL, Barker AR, Oades PJ, Williams CA: Reproducibility of maximal cardiopulmonary exercise testing for young cystic fibrosis patients. J Cyst Fibros 2013;12:644-650.

21 Kent L, O’Neill B, Davidson G, Nevill A, Murray J, Reid A, Elborn JS, Bradley JM: Cycle ergometer tests in children with cystic fibrosis: reliability and feasibility. Pediatr Pulmonol 2012;47:1226-1234.

22 Hulzebos EH, Bomhof-Roordink H, van de Weert-van Leeuwen PB, Twisk JW, Arets HG, van der Ent CK, Takken T: Prediction of mortality in adolescents with cystic fibrosis. Med Sci Sports Exerc 2014;46:20472052.

23 Bongers BC, van Brussel M, Hulzebos HJ, Takken T: Paediatric exercise testing in clinics and classrooms: a comparative review of different assessments. OA Epidemiology 2013;1:14.

24 Williams CA, Saynor ZL, Tomlinson OW, Barker AR: Cystic fibrosis and physiological responses to exercise. Expert Rev Respir Med 2014;8:751752.

25 Hulzebos HJ, Werkman MS, van Brussel M, Takken T: Towards an individualized protocol for workload increments in cardiopulmonary exercise testing in children and adolescents with cystic fibrosis. J Cyst Fibros 2012;11:550-554. 